\title{
Clinical decision-making approaches by health caregivers of patients with COVID-19
}

\author{
Mohsen Taghadosi ${ }^{1}$, Neda Mirbagher Ajorpaz ${ }^{2}$, Mohammad Aghajani ${ }^{3}, *(0)$
}

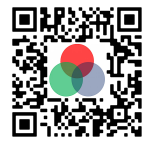

Use your smartphone to scan this QR code and download this article

\begin{abstract}
The Coronavirus disease of 2019 (COVID-19) is the current health crisis in the world- a new, complex phenomenon that has affected and hospitalized many people around the world. Health care providers deal with COVID-19 patients daily and care for the patients while there is no definitive cure for it. Clinical decision-making is an important task of health professionals that plays an essential role in preserving the patient's life and providing quality care. Therefore, understanding clinical decision-making approaches by healthcare providers, such as nurses and physicians, especially in crises such as COVID-19, is essential.

Key words: Clinical decision making, COVID-19, health care providers, intuition
\end{abstract}

\begin{abstract}
${ }^{1}$ Trauma Nursing Research Center, Department of Medical Surgical Nursing, School of Nursing and Midwifery, Kashan University of Medical Sciences, Kashan, IR Iran
\end{abstract}

${ }^{2}$ Autoimmune Diseases Research Center, Department of Nursing and Midwifery, Kashan University of Medical Sciences, Kashan, Iran

${ }^{3}$ Infectious Diseases Research Center, Department of Psychiatric Nursing, Kashan University of Medical Sciences, Kashan, IR Iran

Correspondence

Mohammad Aghajani, Infectious Diseases Research Center, Department of Psychiatric Nursing, Kashan University of Medical Sciences, Kashan, IR Iran

Email: aghajani1362@yahoo.com; aghajani_m@kaums.ac.ir

\section{History}

- Received: Sep 07, 2020

- Accepted: Oct 15, 2020

- Published: Oct 31, 2020

DOI : 10.15419/bmrat.v7i10.641

\section{Check for updates}

\section{Copyright}

(๑) Biomedpress. This is an openaccess article distributed under the terms of the Creative Commons Attribution 4.0 International license.

\section{INTRODUCTION}

The Coronavirus disease of 2019 (COVID-19) pandemic is the current health crisis in the world ${ }^{1}$. The pandemic has affected people of all nations, continents, races, and socioeconomic groups ${ }^{2}$. By September 08,2020 , about 27,332,199 patients in the word were affected by severe acute respiratory syndrome, about 893,700 nationwide deaths had been reported due to COVID-19, about 19,410,434 COVID-19 patients had recovered and were discharged from hospitals, and more people with severe conditions were still hospitalized (WHO, 2020). Despite worldwide preventive measures, as well as individual and public precautions, significant numbers of people were still infected, hospitalized, and dying around the world. The global COVID-19 mortality rate is between 3\% and $15 \%{ }^{1}$.

The treatment team includes nurses and physicians as the front line of care, and their quality of practice is a meaningful indicator of quality of care across healthcare systems ${ }^{3}$. They provide a substantial role in the care of COVID-19 patients. However, there is no guideline for patient care and clinical decisionmaking for nurses during the COVID-19 crisis.

Clinical decision-making is a phenomenon that is fundamental to healthcare practice. It influences the entire spectrum of healthcare practitioners and nurses as frontline clinicians are faced with important clinical decisions on a daily basis ${ }^{4}$. The overall goal of clinical decision-making is to provide the highest quality of patient care based on the available resources. Nurses are accountable for saving lives of patients, the general public, the profession, and the organizations in which they work. Therefore, it is essential to have an understanding of their clinical decision-making approaches, especially in crises such as COVID-19.

In the literature, two models of decision-making have been widely recognized: the information-processing model (analytical model) and the intuitive-humanist model (intuitive model) ${ }^{5}$. Analytical thinking is a logical and linear model of thinking that focuses on objective data. Intuitive thinking is an unconscious process that occurs rapidly and is rooted in experience and emotion ${ }^{6}$. Researchers have indicated that relying on intuition in decision-making can be more effective, reliable, and trustworthy compared to using objective data and logical thinking. They believe that the outcomes of intuitive thinking are comparable with analytical thinking, but information processing and cognitive efforts in intuitive thinking are faster and more efficient ${ }^{7,8}$. In life-threatening conditions and crises, as well as situations wherein there is a need for creativity and innovation, nurses use intuition in their decision-making. Evidence also indicates that in complicated clinical situations due to ethical conflicts, nurses benefit from intuition for moral decision-making and best practices ${ }^{9}$. Therefore, in critical health conditions, intuition is essential for caregivers to improve quality of care, manage crises, and diagnose patients' conditions, as well as to help reduce mortality rates ${ }^{10}$. Currently, nurses around the world are dealing with COVID-19, a disease that continuously demonstrates a variety of unknown and newly-known features. In this condition, because of 
a lack of knowledge and clinical guidelines, nurses' clinical decision-making and use of intuition in their decision-making play an important role in management of the disease outcomes and community health. Clinical decision-making methods are especially important in critical care units. For example, among ICU nurses who provide care for severely ill or injured patients, accuracy and speed are exclusively crucial, which should be considered in clinical decisionmaking and practice ${ }^{11}$.

Nursing practice related to COVID-19 is a new experience; thus, there is a lack of knowledge about approaches of clinical decision-making. Intuition is recognized as an important type of knowledge and a valid method of knowledge in clinical practice. Indeed, intuition is linked to improved clinical judgment, effective decision-making, and overcoming crises. Taking all the statements into account, in novel and complex conditions, such as the COVID-19 crisis where there is a lack in knowledge, intuition can be used to improve clinical decision-making. To realize and use intuition in clinical decision-making practices, we need to examine the process and how it is used in critical situations in the clinic, integrating live experiences into the body of knowledge, and developing theories to describe it. Therefore, the attention of researchers and clinical managers should be increasingly drawn to this important decision-making approach in the care of COVID-19 patients.

\section{ABBREVIATIONS}

COVID-19: Coronavirus disease 2019

\section{ACKNOWLEDGMENTS}

This study approved by the Research Deputy of Kashan University of Medical Sciences, Grant No: 98102. The researchers would like to express their gratitude to the nurses of hospitals of Kashan, Iran.

\section{AUTHOR'S CONTRIBUTIONS}

All authors equally contributed in this article. All authors read and approved the final manuscript.

\section{FUNDING}

None.

\section{AVAILABILITY OF DATA AND MATERIALS}

Not applicable.

\section{ETHICS APPROVAL AND CONSENT TO PARTICIPATE}

Not applicable.

\section{CONSENT FOR PUBLICATION}

Not applicable.

\section{COMPETING INTERESTS}

The authors declare that they have no competing interests.

\section{REFERENCES}

1. Liao X, Wang B, Kang Y. Novel coronavirus infection during the 2019-2020 epidemic: preparing intensive care units-the experience in Sichuan Province, China. Intensive care medicine. 2020;46(2):357-360. PMID: 32025779. Available from: https: //doi.org/10.1007/s00134-020-05954-2.

2. Shanafelt T, Ripp J, Trockel M. Understanding and addressing sources of anxiety among health care professionals during the COVID-19 pandemic. Jama. 2020;323(21):2133-2134. PMID: 32259193. Available from: https://doi.org/10.1001/jama.2020. 5893.

3. Mo Y, Deng L, Zhang L, Lang Q, Liao C, Wang N, Qin M, Huang $\mathrm{H}$. Work stress among Chinese nurses to support Wuhan in fighting against COVID-19 epidemic. Journal of Nursing Management. 2020;28(5):1002-1009. PMID: 32255222. Available from: https://doi.org/10.1111/jonm.13014.

4. Tanner CA. Thinking like a nurse: A research-based model of clinical judgment in nursing. Journal of nursing education. 2006;45(6):204-211. PMID: 16780008. Available from: https: //doi.org/10.3928/01484834-20060601-04.

5. Banning M. A review of clinical decision making: models and current research. Journal of clinical nursing. 2008;17(2):187195.

6. Chilcote DR. Intuition: A concept analysis. In Nursing Forum. 2017;52(1):62-67.

7. Kahneman D, Klein G. Conditions for intuitive expertise: a failure to disagree. American psychologist. 2009;64(6):515. PMID: 19739881. Available from: https://doi.org/10.1037/a0016755.

8. Waks LJ. Intuition in education: Teaching and learning without thinking. Philosophy of Education Archive. 2006;p. 379388.

9. Sofaer B. Enhancing humanistic skills: an experiential approach to learning about ethical issues in health care. Journal of medical ethics. 1995;21(1):31-34. PMID: 7776345. Available from: https://doi.org/10.1136/jme.21.1.31.

10. Demir Y, Denat Y, Khorshid L, Eser I. Cultural validation of the "use of intuition by nursing students scale-Turkish version". Journal of Transcultural Nursing. 2012;23(4):369-376. PMID: 22865202. Available from: https://doi.org/10.1177/ 1043659612451257.

11. Valiee $S$, Negarandeh R, Dehghan Nayeri N. Exploration of Iranian intensive care nurses' experience of end-of-life care: a qualitative study. Nursing in critical care. 2012;17(6):309315. PMID: 23061621. Available from: https://doi.org/10.1111/ j.1478-5153.2012.00523.x. 